\title{
A New Aspect on the Mechanism of Intestinal Cholesterol Absorption in Rat
}

\author{
Makoto Watanabe, Tsuneyuki OKu, Yoshihiro SHIDOJI, \\ and Norimasa HosOYA ${ }^{1}$ \\ Department of Nutrition, School of Health Sciences, \\ Faculty of Medicine, University of Tokyo, \\ Bunkyo-ku, Tokyo 113, Japan
}

(Received August 1, 1980)

Summary In order to study the mechanism of intestinal cholesterol absorption, the relationship between the amount of cholesterol administered and the rate of absorption was investigated by the dual isotope plasma ratio method in vivo and the ligated-loop method in situ. The energy requirement of cholesterol absorption was also observed by means of the ligated-loop method. The results obtained are summarized below. 1) Tri-phase absorption was observed by the dual isotope plasma ratio method. When less than $300 \mu \mathrm{g}$ of cholesterol was administered, absorption increased linearly, with the coefficient of absorption being more than $80 \%$. When the amount administered was between 300 and $500 \mu \mathrm{g}$, the absorption was constant. With the administration of more than $500 \mu \mathrm{g}$, absorption increased linearly, but the coefficient of absorption decreased to approximately $55 \%$.

2) With the ligated-loop method, a second saturation profile was obtained when between 250 and $400 \mu \mathrm{g}$ of cholesterol was administered to a segment. When 50 to $250 \mu \mathrm{g}$ of cholesterol were administered, absorption increased in proportion to the increase in cholesterol dosage.

3) The mucosal uptake of cholesterol decreased to $40-60 \%$ of the control with the addition of metabolic inhibitors such as $\mathrm{NaN}_{3}, \mathrm{KCN}, 2,4-\mathrm{DNP}$ and ouabain, whereas the uptake of palmitate showed no significant decrease. In addition, the uptake of cholesterol decreased remarkably to $25 \%$ of the control with the lowering of body temperature from $37^{\circ} \mathrm{C}$ to $27 \mathrm{C}$.

These results suggest the existence of an active transport system which has a limited capacity for cholesterol absorption and which requires energy for its operation in the physiological state.

Key Words cholesterol, $\beta$-sitosterol, intestine, inhibition, active transport, energy-dependent, cholesterol absorption, intestinal mucosa, mucosal uptake

\footnotetext{
1 渡部 誠, 奥 恒行, 四童子好広, 細谷憲政
} 
Cholesterol has been thought to be transported into the intestinal epithelial cells by a passive diffusion process, since cholesterol absorption in the intestine increases linearly corresponding to the amount of dietary cholesterol (1-3). Some phenomena contradictory to the passive diffusion theory of intestinal transport of cholesterol have, however, been observed. Chow and Hollander have reported that the free energy for the cholesterol uptake into the intestinal mucosa was much larger than the value which was calculated according to the simple diffusion theory (4). Sylvén and Borgström have demonstrated that the coefficient of cholesterol absorption is much higher than that of $\beta$-sitosterol, an analogue of cholesterol (5). Additionally, cholesterol absorption is competitively inhibited by $\beta$-sitosterol (6). Therefore, it is not yet clear whether the intestinal absorption of cholesterol is dependent on a passive diffusion mechanism or on an active transport process which requires energy and of limited capacity.

Recently, Zilversmit et al. have developed a dual isotope plasma ratio method as a new technique for the measurement of the intestinal absorption in vivo of cholesterol in rats $(7,8)$. Sylvén evaluated the in situ intestinal ligated-loop method as most convenient to study the mucosal uptake of cholesterol $(9,10)$. These two methods have been judged more reliable and useful than the everted gut sac and the lymph-duct fistula methods in determining the absorption and the uptake of cholesterol in the physiological state. Therefore, it would seem appropriate to study the mechanism of intestinal cholesterol absorption by using these methods.

The present paper describes the relationship between the amount of cholesterol administration and absorption and suggests the existence of an energy-dependent transport process for cholesterol absorption.

\section{METHODS}

1. Chemicals and animals. $\left[7-{ }^{3} \mathrm{H}\right]$ Cholesterol $(21.5 \mathrm{Ci} / \mathrm{mmol})$ and $\left[1-{ }^{14} \mathrm{C}\right]-$ palmitate $(0.054 \mathrm{Ci} / \mathrm{mmol})$ were obtained from New England Nuclear Co. (Boston, MA), and $\left[4-{ }^{14} \mathrm{C}\right]$ cholesterol $(0.057 \mathrm{Ci} / \mathrm{mmol})$ was obtained from Amersham/Searle Co. (Arlington Hights, IL). The purity of these radioactive compounds was tested by thin layer chromatography on Silica gel G (Merck Co., Darmstadt, Germany) with a solvent system of benzene : ethylacetate $=2: 1(\mathrm{v} / \mathrm{v})$. Compounds found to be more than $98 \%$ pure were used in all experiments.

Glycerol monooleate and glycochenodeoxycholate were obtained from Sigma Chem. Co. (St. Louis, MO), Omunifluor from New England Nuclear Co., and sodium azide $\left(\mathrm{NaN}_{3}\right)$ from Merck Co. Potassium cyanide $(\mathrm{KCN})$ was purchased from Kishida Chem. Indust. Co. (Tokyo, Japan), 2, 4-dinitrophenol (2,4-DNP) from Wako Pure Chem. Co. (Tokyo, Japan), and ouabain from Tokyo Kasei Co. (Tokyo, Japan). All other chemicals employed were of analytical grade.

2. Preparation of micellar dose solution. Micellar dose solutions containing $\left[{ }^{14} \mathrm{C}\right]$ cholesterol $(0.01$ to $1.0 \mu \mathrm{Ci} / 0.5 \mathrm{ml})$ were prepared by dissolving appropriate amounts of non-radioactive cholesterol and $5 \mathrm{~mm}$ glycerol monooleate in $50 \mathrm{~mm}$ 
glycochenodeoxycholic acid. $\left[{ }^{14} \mathrm{C}\right]$ Palmitate was used instead of $\left[{ }^{14} \mathrm{C}\right]$ cholesterol in some experiments. These solutions were incubated at $37^{\circ} \mathrm{C}$ overnight to produce stable micellar particles.

In the experiments to study the effect of metabolic inhibitors on mucosal uptake of cholesterol, $40 \mathrm{~mm}$ sodium azide, $40 \mathrm{~mm}$ potassium cyanide, $20 \mathrm{~mm}$ 2, 4dinitrophenol, or $5 \mathrm{~mm}$ ouabain was dissolved in $0.5 \mathrm{ml}$ of the micellar solution containing $10 \mu \mathrm{g}$ or less of cholesterol or palmitate.

3. Dual isotope plasma ratio method. The measurement of intestinal cholesterol absorption was carried out in vivo by the dual isotope plasma ratio method of Zilversmit et al. with slight modifications (7). Under light anesthesia with ethylether, the abdominal cavity was opened by incision, and $1.0 \mu \mathrm{Ci}$ of $\left[{ }^{14} \mathrm{C}\right]$ cholesterol in $0.5 \mathrm{ml}$ of micellar solution was administered into the duodenum. $1.0 \mu \mathrm{Ci}$ of $\left[{ }^{3} \mathrm{H}\right]$ cholesterol dispersed in $0.5 \mathrm{ml}$ of serum obtained previously from the test animal was then immediately injected into the left external jugular vein. The rat was subsequently fed on standard diet and water ad libitum. Samples of blood $(2 \mathrm{ml})$ were collected with heparinized syringes from the right external jugular vein of the rat at 48, 72 and $96 \mathrm{hr}$ after the administration of cholesterol. The radioactive cholesterol was extracted from the plasma samples $(1 \mathrm{ml}$ each) with $3 \mathrm{ml}$ of ethanol:hexane $=$ $2: 1(\mathrm{v} / \mathrm{v})$ after saponification with $50 \%$ potassium hydroxide at $50^{\circ} \mathrm{C}$ for $30 \mathrm{~min}$. The radioactivities of $\left[{ }^{3} \mathrm{H}\right]$ cholesterol and $\left[{ }^{14} \mathrm{C}\right]$ cholesterol were then determined simultaneously in $7 \mathrm{ml}$ of toluene-based scintillation cocktail containing $0.4 \%$ Omunifluor by a Packard Tri-Carb liquid scintillation spectrometer, Model 3380 (Packard Co., Downers Grove, IL). The counting efficiencies were $55 \%$ for ${ }^{14} \mathrm{C}$ and $40 \%$ for ${ }^{3} \mathrm{H}$, respectively. Percent absorption of cholesterol was calculated $(7,11)$ as follows:

$$
\% \text { absorption }=\frac{\text { plasma }{ }^{14} \mathrm{C}(\mathrm{dpm}) / \operatorname{dosed}{ }^{14} \mathrm{C}(\mathrm{dpm})}{\text { plasma }{ }^{3} \mathrm{H}(\mathrm{dpm}) / \operatorname{dosed}{ }^{3} \mathrm{H}(\mathrm{dpm})} \times 100
$$

4. Intestinal ligated-loop method. The measurements of mucosal uptake of cholesterol were carried out in situ by the ligated-loop method of Sylvén(9). After an animal was well anesthesized with nembutal $(30 \mathrm{mg} / \mathrm{kg}$ of body weight), 4 to 6 segments of $4 \mathrm{~cm}$ length were made in the jejunum while maintaining the circulation of blood and lymph. One hundredth $\mu \mathrm{Ci}$ of $\left[{ }^{14} \mathrm{C}\right]$ cholesterol in $0.5 \mathrm{ml}$ of dose solution was injected into each segment and then incubated in the body for $30 \mathrm{~min}$, after closing the abdominal wall. To investigate the effect of metabolic inhibitors on cholesterol uptake, a micellar dose solution without the inhibitor (control) and a solution with one of the inhibitors were injected simultaneously into different segments of the same rat. In the experiments to compare the coefficient of absorption of cholesterol with that of palmitate, either $\left[{ }^{14} \mathrm{C}\right]$ cholesterol or $\left[{ }^{14} \mathrm{C}\right]$ palmitate was injected simultaneously into different jejunal segments of the same animal. After incubation for $30 \mathrm{~min}$, each segment of the jejunal loop was removed from the body and washed with $2 \mathrm{ml}$ of ice-chilled physiological saline solution. The tissue.was further washed 5 times with $2 \mathrm{ml}$ of of ice-chilled $5 \mathrm{~mm}$ 
sodium deoxycholate in saline solution to remove the radioactive materials remaining on the surface of the mucosa. Each sample of washed tissue weighed between 200 and $400 \mathrm{mg}$. The radioactive material in the tissue was extracted with $9 \mathrm{ml}$ of chloroform: ethanol $=2: 1(\mathrm{v} / \mathrm{v})$ as described by Folch et al.(12). After evaporating the chloroform, the radioactivity was determined in $10 \mathrm{ml}$ of toluenebased scintillation cocktail by a liquid scintillation spectrometer. The counting efficiency was about $90 \%$.

The amount of cholesterol or palmitate incorporated into the tissue was calculated and expressed as $\mu \mathrm{g} / 100 \mathrm{mg}$ tissue $/ 30 \mathrm{~min}$. The ratio of inhibition by the metabolic inhibitor was calculated by dividing the amount of cholesterol uptake in the presence of inhibitor by the amount of cholesterol uptake in the absence of inhibitor with the resulting value expressed as $\%$ of the control. The same procedure was used to compare the coefficient of uptake of cholesterol with that of palmitate.

In order to observe the effect of temperature on the mucosal uptake, the body temperature of the animal was kept at $27^{\circ} \mathrm{C}$ with crushed ice, and the rate of uptake was compared with that at $37^{\circ} \mathrm{C}$.

\section{RESULTS}

1. Relationship between the amount of cholesterol administered and the coefficient of absorption of cholesterol

In order to observe the relationship between the amount of cholesterol

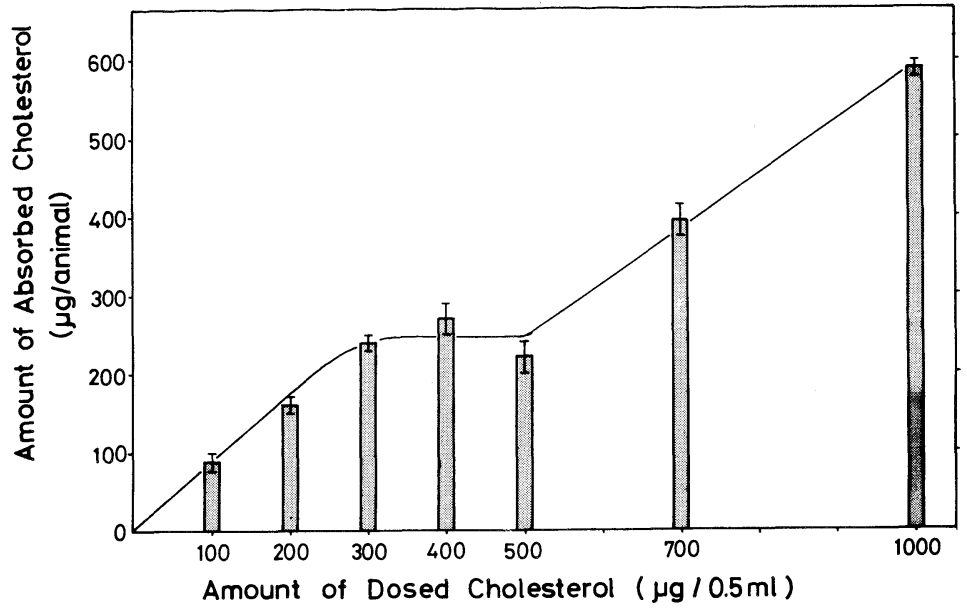

Fig. 1. The effect of varying amounts of administered cholesterol on the coefficient of cholesterol absorption in vivo. From $50 \mu \mathrm{g}$ to $1,000 \mu \mathrm{g}$ of $\left[4-{ }^{14} \mathrm{C}\right]$ cholesterol $(1.0 \mu \mathrm{Ci}$ each) in $0.5 \mathrm{ml}$ of micellar solution was injected intraduodenally and cholesterol absorption was measured by the dual isotope plasma ratio method. The values are the means of 5-9 determinations and expressed as $\mu \mathrm{g}$ of cholesterol absorption per rat. 


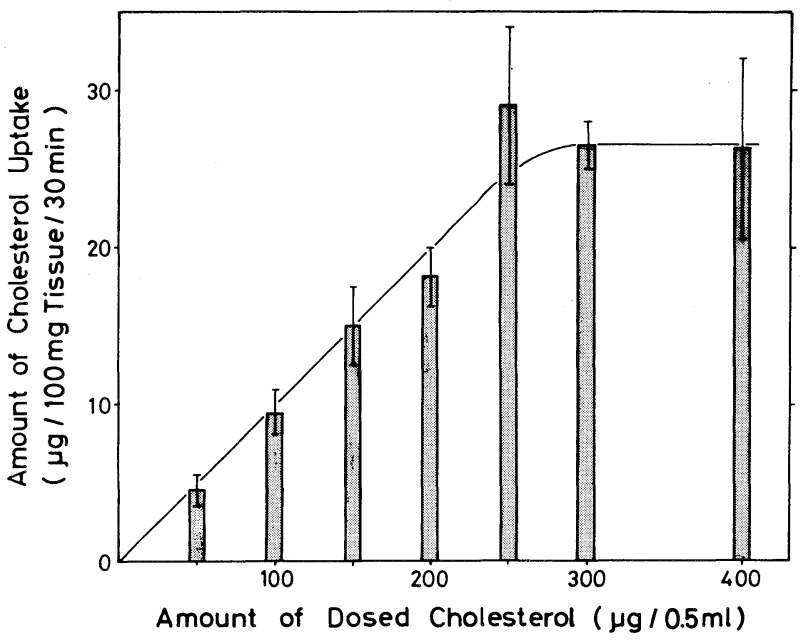

Fig. 2. The effect of varying amounts of administered cholesterol on the coefficient of cholesterol uptake by jejunal segments. From $10 \mu \mathrm{g}$ to $400 \mu \mathrm{g}$ of $\left[4-{ }^{14} \mathrm{C}\right]$ cholesterol $(0.01 \mu \mathrm{Ci}$ each) dissolved in $0.5 \mathrm{ml}$ of the dose solution was injected into a jejunal segment and the cholesterol uptake was measured in situ by the ligated-loop method. The values are the means of 9-13 determinations and are expressed as $\mu \mathrm{g}$ of cholesterol uptake per $100 \mathrm{mg}$ tissue per $30 \mathrm{~min}$.

administered and absorption, 100 to $1,000 \mu \mathrm{g}$ of cholesterol in $0.5 \mathrm{ml}$ of dose solution were directly injected into a rat jejunum, and the intestinal absorption was measured by the dual isotope plasma ratio method. In the lower range (less than $300 \mu \mathrm{g} / 0.5 \mathrm{ml} / \mathrm{rat}$ ) of administration, absorption increased linearly according to the amount administered (Fig. 1). When the amount was between $300 \mu \mathrm{g}$ and $500 \mu \mathrm{g}$, the absorption was constant. In rats given $300 \mu \mathrm{g}$ of cholesterol, about $250 \mu \mathrm{g}$ was absorbed. When the amount was increased to more than $500 \mu \mathrm{g} / 0.5 \mathrm{ml} / \mathrm{rat}$, the absorption increased again linearly (Fig. 1). These results indicate that the intestinal absorption of cholesterol increases linearly at both low and high dosage levels but saturation takes place at intermediate dosage levels.

The mucosal uptake of cholesterol was also measured by means of the ligatedloop method with the administration of $10 \mu \mathrm{g}$ to $400 \mu \mathrm{g}$ cholesterol in $0.5 \mathrm{ml}$ of dose solution. The mucosal uptake increased on linear relation to the dose level from $10 \mu \mathrm{g}$ up to $250 \mu \mathrm{g}$ cholesterol (Fig. 2). In the range of $250 \mu \mathrm{g}$ through $400 \mu \mathrm{g}$ of cholesterol, the mucosal uptake was clearly saturated.

From these results, it appears that the saturation of cholesterol absorption occurs at concentrations between $250 \mu \mathrm{g}$ and $500 \mu \mathrm{g}$ of cholesterol for both the dual isotope plasma ratio method in vivo and the jejunal ligated-loop method in situ. Therefore, it seems to be possible to investigate the mechanism of cholesterol absorption in the physiological state using the ligated-loop method. 
Table 1. The effect of metabolic inhibitors on cholesterol uptake.

Cholesterol uptake into the mucosa of jejunal segments was measured in the presence or the absence of inhibitors in situ by the ligated-loop method. Forty millimolar sodium azide, $40 \mathrm{~mm}$ potassium cyanide, $20 \mathrm{~mm}$ 2,4-dinitrophenol, or $5 \mathrm{~mm}$ ouabain was added to the dose solution containing less than $10 \mu \mathrm{g}$ of $\left[4-{ }^{14} \mathrm{C}\right]$ cholesterol in $0.5 \mathrm{ml}$. For the comparative experiment between cholesterol and palmitate, less than $10 \mu \mathrm{g}$ of [1${ }^{14}$ C]palmitate were used instead of cholesterol. The values are the means of $8-10$ determinations and are expressed as $\%$ of the control (that without inhibitor).

\begin{tabular}{lcc}
\hline & \multicolumn{2}{c}{ Uptake } \\
\cline { 2 - 3 } & Cholesterol & Palmitate \\
\hline Control & 100 & 100 \\
$\mathrm{NaN}_{3}(40 \mathrm{~mm})$ & $41.6 \pm 3.2^{\mathrm{a}}$ & $80.9^{\mathrm{c}}$ \\
$\mathrm{KCN}(40 \mathrm{~mm})$ & $38.4 \pm 1.6^{\mathrm{a}}$ & $88.2^{\mathrm{c}}$ \\
$2,4-D N P(20 \mathrm{~mm})$ & $61.3 \pm 20.0^{\mathrm{b}}$ & $85.5^{\mathrm{c}}$ \\
Ouabain $(5 \mathrm{~mm})$ & $60.2 \pm 10.0^{\mathrm{b}}$ & $85.0^{\mathrm{c}}$ \\
\hline
\end{tabular}

Significantly different from control ${ }^{\mathrm{a}} p<0.01 ;{ }^{\mathrm{b}} p<0.05 ;{ }^{\mathrm{c}}$ N.S.

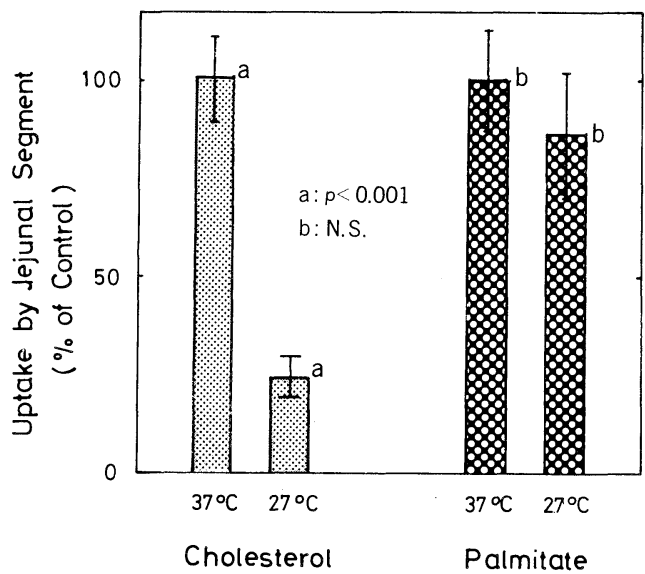

Fig. 3. The effect of low temperature on cholesterol uptake. Body temperature of the rats was kept at $27 \pm 1.0^{\circ} \mathrm{C}$ with ice and the cholesterol uptake was measured in situ by the ligated-loop method. A half milliliter of the dose solution containing less than $10 \mu \mathrm{g}$ of $\left[4-{ }^{14} \mathrm{C}\right] \mathrm{cholesterol}$ was injected into the jejunal segment. For the comparative experiment to study the specificity of cholesterol uptake, less than $10 \mu \mathrm{g}$ of [1$\left.{ }^{14} \mathrm{C}\right]$ palmitate were used instead of $\left[{ }^{14} \mathrm{C}\right]$ cholesterol. The values are the means of 6 determinations and are expressed as $\%$ of the control (that at $37^{\circ} \mathrm{C}$ ).

\section{Effect of metabolic inhibitor on mucosal uptake of cholesterol}

The saturable uptake of cholesterol suggests that cholesterol may not be transported by a simple diffusion process. Therefore, the effect of metabolic inhibitors on the mucosal uptake was studied using the ligated-loop method. As shown in Table 1, cholesterol uptake by the jejunal segments decreased significantly 
with all metabolic inhibitors such as sodium azide, potassium cyanide, 2, 4dinitrophenol or ouabain. In contrast, the mucosal uptake of palmitate, which is thought to be transported by a simple diffusion process, showed no significant decrease with the addition of inhibitors (Table 1). These results suggest that an energy-dependent system is involved in the process of intestinal cholesterol uptake.

\section{The effect of body temperature on mucosal uptake of cholesterol}

The effect of body temperature on cholesterol uptake was observed by means of the ligated-loop method. When the body temperature of an animal was lowered to $27^{\circ} \mathrm{C}$, cholesterol uptake decreased significantly compared to the control (that at $37^{\circ} \mathrm{C}$ ) though the uptake of palmitate was not inhibited at the low temperature (Fig. 3 ). These results also support the hypothesis that an energy-dependent system is involved in the mucosal uptake of cholesterol.

\section{DISCUSSION}

It has been generally accepted that cholesterol is absorbed via simple passive diffusion in the intestine $(1-3)$. Our results have, however, suggested that the intestinal absorption of low levels of cholesterol occurs by an active transport process requiring energy.

It has been previously demonstrated by balance studies and lymph-collection techniques that the coefficient of cholesterol absorption varies widely from $7.5 \%$ to $97 \%(13,14)$. However, the acceptable value of the coefficient is $40-60 \%$ as Zilversmit et al. have demonstrated by means of the dual isotope plasma ratio method (8). In these papers, it has been generally believed that the coefficient of cholesterol absorption was a constant independent of the amount administered.

In our results, cholesterol absorption did not simply increase according to the increment of cholesterol dosage, but instead showed a tri-phase relationship (Fig. 1). When cholesterol amounting to more than $500 \mu \mathrm{g} / 0.5 \mathrm{ml} / \mathrm{rat}$ was administered, the coefficient of absorption was about $55 \%$, independent of the amount administered. This value agrees acceptably with that reported by others $(8,15)$. The coefficient of absorption was, however, greater than $80 \%$ for low levels of administration (less than $300 \mu \mathrm{g} / 0.5 \mathrm{ml} / \mathrm{rat}$ ), and was remarkably different from that observed with high levels of administration (more than $500 \mu \mathrm{g} / 0.5 \mathrm{ml} / \mathrm{rat}$ ). Thus, our results suggest that the coefficient of absorption varies substantially when the amount of cholesterol administration exceeds the physiological dose level. In other papers reporting a linear increase in cholesterol absorption independent of the amount of administration (1-3), more than $10 \mathrm{mg}$ of cholesterol was given to each animal. This dose level is 10-20 times greater than the dosage in our experiments. Therefore, it appears that the saturable phase in cholesterol absorption was not detected by other groups, because the phenomenon occurs only at low dosage levels. Dosages of more than $1.0 \mathrm{mg}$ of cholesterol are excessively large in comparison with the normal daily dietary intake in the physiological state of animal and would 
appear inappropriate for studying the absorption process.

Hollander and Muralidhara have demonstrated that the intestinal absorption of retinol, one of the water-insoluble materials, saturates once at low concentrations and then is enhanced again above a certain level with increasing levels of administration (16). The mucosal uptake of $\beta$-sitosterol, an analogue of cholesterol, however, showed no saturation throughout a wide range of administration (from $10 \mu \mathrm{g}$ to $500 \mu \mathrm{g}$ in $0.5 \mathrm{ml}$ of dose solution) (17). Therefore, saturation at low dose levels appears to be a phenomenon characteristic of the intestinal absorption of only certain materials such as cholesterol and retinol.

Using the intestinal ligated-loop method, Sylven has indicated that the mucosal uptake of cholesterol decreases remarkably when the blood flow to the ligated-loop segments is interrupted (10). This suggests that the cholesterol uptake system is energy-dependent. In our observations, the uptake of palmitate showed no significant decrease with the addition of metabolic inhibitors or with the lowering of body temperature, whereas cholesterol uptake significantly decreased. This was the case even when palmitate was simultaneously injected into different segments of the same animal while the cholesterol was administered. Present results strongly support Sylven's suggestion that the mucosal uptake of cholesterol requires energy. At the same time, the energy-dependent absorption seems to be a phenomenon specific to cholesterol, but not to $\beta$-sitosterol or palmitate.

Vahouny et al. have reported that the lymphatic transport of cholesterol is prevented by puromycin, an inhibitor of protein synthesis, and that about $80 \%$ of cholesterol in the lymph fluid is in the form of free cholesterol. They suggested that the inhibitory effect of puromycin was related to chylomicron synthesis, and further that the cholesterol incorporated into intestinal epithelial cells was released in the form of free cholesterol rather than the esterified form (18). In our experiments, when the mucosal uptake of cholesterol in the absence of metabolic inhibitor was measured by the ligated-loop method, a saturable uptake was observed, and the radioactive cholesterol incorporated could not be detected in the blood during incubation for $30 \mathrm{~min}$. Furthermore, the radioactive cholesterol in the extract from intestinal mucosa was mostly of the free form in thin layer chromatography. Therefore, our results indicate that the step of mucosal uptake is one of the limiting stages in the process of cholesterol absorption, but the esterification of cholesterol is not, and that the decrease in uptake by metabolic inhibitors is not related to the process of transport into the lymph.

In our previous paper $(6), \beta$-sitosterol showed a varying inhibitory effect on the intestinal absorption of cholesterol according to the stage of mucosal uptake. Additionally, it was demonstrated in the present report that the process of cholesterol uptake is saturable and requires energy. These observations strongly suggest that there is a specific carrier in the intestinal mucosa for cholesterol as well as some other nutrients. The carrier involved in this active transportation of cholesterol may be a specific binding protein. 


\section{REFERENCES}

1) Glover, J., and Morton, R. A. (1958): The absorption and metabolism of sterols. Brit. Med. Bull., 14, 226-233.

2) Sylvén, C., and Borgström, B. (1968): Absorption and lymphatic transport of cholesterol in the rat. J. Lipid Res., 9, 596-601.

3) Mattson, F. H., Volpenhein, R. A., and Erickson, B. A. (1977): Effect of plant sterol esters on the absorption of dietary cholesterol. J. Nutr., 107, 1139-1146.

4) Chow, S. L., and Hollander, D. (1978): Initial cholesterol uptake by everted sacs of rat small intestine. Kinetic and thermodynamic aspects. Lipids, 13, 239-244.

5) Sylvén, C., and Borgström, B. (1969): Absorption and lymphatic transport of cholesterol and sitosterol in the rat. J. Lipid Res., 10, 179-182.

6) Shidoji, Y., Watanabe, M., Oku, T., Muto, Y., and Hosoya, N. (1980): Inhibition of $\beta$ sitosterol on intestinal cholesterol absorption in rat using in vivo dual isotope ratio method. J. Nutr. Sci. Vitaminol., 26, 183-188.

7) Zilversmit, D. B. (1972): A single blood sample dual isotope method for the measurement of cholesterol absorption in rats. Proc. Soc. Exp. Biol. Med., 140, $862-865$.

8) Zilversmit, D. B., and Huges, L. B. (1974): Validation of a dual isotope plasma ratio method for measurement of cholesterol absorption in rats. J. Lipid Res., 19, 82-93.

9) Sylvén, C. (1971): Uptake of micellar lipids by small intestinal segments. [Under differental experimental conditions] Acta Physiol. Scand., 83, 289-299.

10) Sylvén, C. (1970): Influence of blood supply on lipid uptake from micellar solutions by the rat small intestine. Biochim. Biophys. Acta, 203, 365-375.

11) Samuel, P., Crouse, J. R., and Ahrens, E. H., Jr. (1978): Evaluation of an isotope ratio method for measurement of cholesterol absorption in man. J. Lipid Res., 15, 465-473.

12) Folch, J., Lees, M., and Sloane Stanley, G. H. (1956): A simple method for the isolation and purification of total lipids from animal tissues. J. Biol. Chem., 226, 497-509.

13) Wells, W. W., Anderson, S. C., and Ma, R. Q. (1960): Lactose diets and cholesterol metabolism. 1. Cholesterol metabolism and bile acid excretion in the rat. J. Nutr., 71, 405-410.

14) Lutton, C. (1976): The role of the digestive tract in cholesterol metabolism. Digestion, 14, 342-356.

15) Borgström, B. (1968): Quantitative aspects of the intestinal absorption and metabolism of cholesterol and $\beta$-sitosterol in the rat. J. Lipid Res., 9, 473-481.

16) Hollander, D., and Muralidhara, K. S. (1977): Vitamin A, intestinal absorption in vivo: Influence of luminal factors on transport. Am. J. Physiol., 232, E471-477.

17) Watanabe, M., Oku, T., and Hosoya, N., unpublished result.

18) Vahouny, G. V., Ito, M., Blendermann, E. M., Gallo, L. L., and Treadwell, C. R. (1977): Puromycin inhibition of cholesterol absorption in the rat. J. Lipid Res., 18, $745-752$. 